\title{
PSMA PET/CT in primary prostate cancer diagnostics: an overview of the literature
}

\author{
Esmée C. A. van der Sar · Ludwike M. van Kalmthout · M. G. E. H. Lam
}

Published online: 7 September 2020

(C) The Author(s) 2020

\begin{abstract}
Imaging with radiotracers targeting the prostate-specific membrane antigen (PSMA) receptor is identified as a promising novel technique in prostate cancer $(\mathrm{PCa})$ detection. In this paper we aim to summarize the current knowledge derived from the literature as well as the authors' experiences on PSMA PET/CT in initial staging of PCa. PSMA PET/CT lesion- and template-based sensitivity and specificity respectively ranged from $35.1-96.1 \%$ and 96-100\%. Patient-based sensitivity and specificity respectively ranged from $33.3-100 \%$ and $95-100 \%$. Accuracy was 92\% (95\% CI 88-95) versus 65\% (95\% CI 60-69) compared to conventional imaging (CT and skeletal scintigraphy). PSMA PET/CT is superior for detection of metastases in primary PCa compared to conventional imaging. Also, PSMA PET/CT has a high specificity and moderate sensitivity for lymph node detection in primary PCa. For adequate initial staging, extended pelvic lymph node dissection (ePLND) will still be required, however, PSMA PET/CT can induce important management changes.
\end{abstract}

Keywords PSMA PET/CT · Primary prostate cancer · Staging $\cdot$ Sensitivity $\cdot$ Specificity

PSMA PET/CT in de diagnostiek van primaire prostaatkanker: een samenvatting van de huidige literatuur

Samenvatting Diagnostiek middels radiotracers die gericht zijn op de prostaatspecifiek membraanantigeen (PSMA) receptor zijn veelbelovend voor de detec-

E. C. A. van der Sar, MD $(\varangle) \cdot$ L. M. van Kalmthout, MD ·

M. G. E. H. Lam, PhD

Dept. of Radiology and Nuclear Medicine, University

Medical Center Utrecht, Utrecht, The Netherlands

e.c.a.vandersar@umcutrecht.nl tie van prostaatkanker. In dit artikel worden de kennis uit de literatuur met betrekking tot primaire stadiëring van prostaatkanker middels PSMA PET/CT en de ervaringen van de auteurs samengevat. De op patiëntinformatie gebaseerde sensitiviteit en specificiteit van PSMA PET/CT was 33,3-100\% en 95-100\%. De op laesie en template gebaseerde sensitiviteit en specificiteit was $35,1-96,1 \%$ en $96-100 \%$. De accuratesse was $92 \%$ (95\%-BI 88-95) versus 65\% (95\%-BI 60-69) in vergelijking met conventionele beeldvorming (CT en skeletscintigrafie). Concluderend is PSMA PET/CT in vergelijking met conventionele beeldvorming superieur voor de detectie van metastasen bij primair prostaatkanker. PSMA PET/CT heeft weliswaar een hoge specificiteit, maar slechts een matige sensitiviteit voor de detectie van lymfekliermetastasen. Daarmee blijft een lymfeklierdissectie nog steeds vereist, hoewel een positieve PSMA PET/CT kan leiden tot beleidsverandering.

Trefwoorden PSMA PET/CT $\cdot$ primaire prostaatkanker · stadiëring · sensitiviteit · specificiteit

\section{Introduction}

Globally, prostate cancer (PCa) is the most commonly diagnosed cancer, affecting 1 in 9 men. With 31,620 estimated deaths in 2019, PCa represents the secondranked cause of cancer mortality [1]. In the Netherlands, approximately 12,420 patients were newly diagnosed in 2018 [2]. Due to aging of the population, this proportion is expected to increase even further in 2025.

Since metastases of PCa are characterized as an adverse prognostic factor [3], accurate staging is essential to select the most effective treatment strategy. To define TNM-stage, current international guidelines recommend intermediate- and high-risk PCa patients 
to undergo X-ray computed tomography (CT) or magnetic resonance imaging (MRI) of the lower abdomen [4]. However, to detect lymph node metastases conventional modalities (CT, MRI) rely on morphologic features: e.g. nodal size and shape. Lymph nodes larger than $8-10 \mathrm{~mm}$. are considered suspicious, while over $80 \%$ of lymph node metastases in PCa are smaller than $8 \mathrm{~mm}$ [5].

To detect pelvic lymph node metastases, a bilateral extended pelvic lymph node dissection (ePLND) is currently considered the gold standard. This surgical procedure is performed if the estimated risk for positive lymph nodes exceeds a locally determined threshold (in the Netherlands 5-15\%) according to the Memorial Sloan Kettering Cancer Center (MSKCC)-nomogram [4]. Since an ePLND is an invasive procedure with possible complications such as lymphedema, nerve injury and thrombosis, reliable imaging modalities for newly diagnosed PCa patients are desirable as an alternative for surgical lymph node staging $[4,6]$.

To detect metastatic bone lesions, skeletal scintigraphy is recommended in intermediate-risk, International Society of Urological Pathology (ISUP) grade 3 (Gleason 4+3) PCa patients and high-risk PCa patients (prostate-specific antigen (PSA) levels $>20 \mathrm{ng} / \mathrm{mL}$, ISUP grade $4 / 5$ (Gleason Score $>7$ ), $>c \mathrm{~T} 2 \mathrm{c}$, or $\mathrm{cN}+$ ) [4]. However, because of the origin of bone metastases in bone marrow, negative skeletal scintigraphy in patients with primary PCa does not exclude presence of bone metastases. Hence, lesions early in the metastatic process, are likely to be missed [7].

During the last decennium, positron emission tomography/computed tomography (PET/CT) emerged as an important new imaging modality, in which morphologic (CT) and molecular (PET) information are merged. The initially used radiotracers (fluor-18 $\left({ }^{18} \mathrm{~F}\right)$ Choline and carbon-11 ( $\left.{ }^{11} \mathrm{C}\right)$-Choline) however, appeared inadequate to detect metastases of $\mathrm{PCa}$, because of their low sensitivity [8]. Past years, imaging with radiotracers targeting the prostate-specific membrane antigen (PSMA) receptor, was identified as a promising novel technique in PCa detection [9]. Consequently, imaging with PSMA PET/CT has been (inter)nationally implemented in the diagnostic workup of PCa $[4,10]$. In this paper, we aim to summarize the current literature as well as the authors' experience on PSMA PET/CT imaging in initial staging of PCa.

\section{Prostate specific membrane antigen}

PSMA is a type II transmembrane glycoprotein, expressed by the apical side of benign prostate epithelium. The PSMA receptor is significantly overexpressed in $90 \%$ of the PCa cells and its expression tends to increase 100-1000 times with the aggressiveness of the tumor (e.g. Gleason score or extent of metastases) [11]. Since labeled PSMA tracers bind

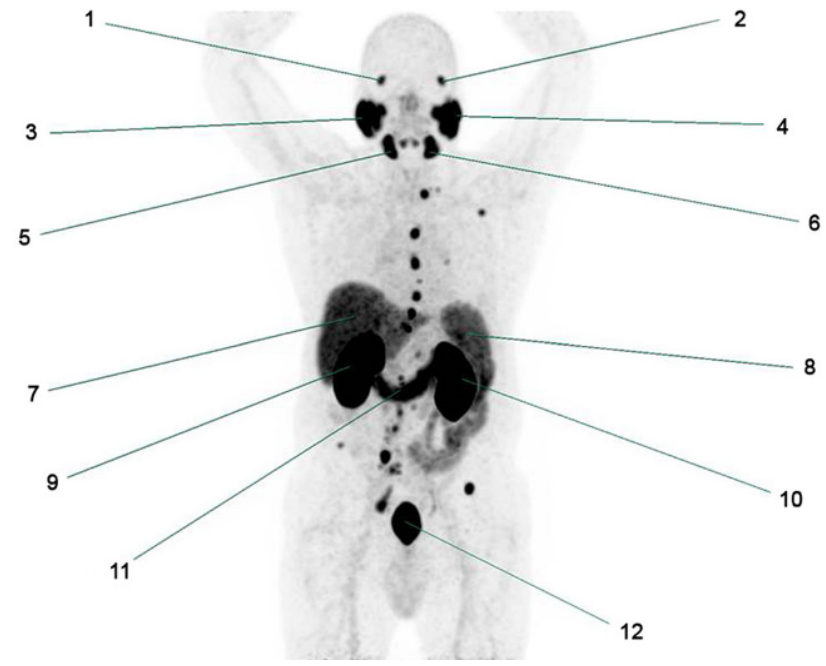

Fig. 1 Frontal image of ${ }^{68} \mathrm{Ga}-\mathrm{PSMA}$ Maximal Intensity Projection (MIP) representing the uptake of PSMA in healthy tissue in a patient suspected for PCa metastases. All numbers represent healthy tissue. Non-specified areas with high activity are suspected for PCa metastases. 1. Right lacrimal gland, 2. Left lacrimal gland, 3. Right parotid gland, 4. Left parotid gland, 5. Right submandibular gland, 6. Left submandibular gland, 7. Liver, 8. Spleen, 9. Right kidney, 10. Left kidney, 11. Duodenum, 12. Urine bladder

with a high affinity to the PSMA receptor, they represent an attractive target for nuclear (PET) imaging. Although its specific role has not been clarified yet, the protein contributes to glutamatergic neurotransmission and folate absorption [12]. PSMA is also physiologically expressed in the salivary and lacrimal glands, kidneys, central nervous system, duodenum and colon as shown in Fig. 1 [13].

\section{Clinical practice}

\section{Different PSMA tracers}

To date, two types of PSMA tracers are used in the Netherlands, i.e. Gallium-68 $\left({ }^{68} \mathrm{Ga}\right)$-labelled PSMA tracers (i.e. $\quad{ }^{68} \mathrm{Ga}-\mathrm{PSMA}-\mathrm{HBED}-\mathrm{CC} /{ }^{68} \mathrm{Ga}-\mathrm{PSMA}-11$, ${ }^{68} \mathrm{Ga}-\mathrm{PSMA}-617$ and ${ }^{68} \mathrm{Ga}$-PSMA I\&T) and ${ }^{18}$ Flourine $\left({ }^{18} \mathrm{~F}\right)$-labelled PSMA tracers (i.e. ${ }^{18} \mathrm{~F}$-DCFPyL, ${ }^{18} \mathrm{~F}$-DCFBC and ${ }^{18}$ F-PSMA-1007) as shown in Figs. 2 and 3. These radiotracers have different characteristics. Firstly, ${ }^{68} \mathrm{Ga}-\mathrm{PSMA}$ can be produced on site if a Germanium68 generator is available; ${ }^{18} \mathrm{~F}$-PSMA is a cyclotron product and must be purchased. Secondly, ${ }^{18} \mathrm{~F}$ has a longer half life (110 minutes) compared to ${ }^{68} \mathrm{Ga}$ (68 minutes), which allows for transportation to surrounding hospitals. Thirdly, in absence of a positron range effect, ${ }^{18} \mathrm{~F}$-PSMA has a higher image resolution compared to ${ }^{68} \mathrm{Ga}$-PSMA. Also, ${ }^{18} \mathrm{~F}$-PSMA has a lower positron emission energy of $0.65 \mathrm{MeV}$ compared to ${ }^{68} \mathrm{Ga}-\mathrm{PSMA}(1.90 \mathrm{MeV})$, which is assumed to result in higher imaging quality [14-16]. 
<smiles>CC(C)C[N+]1(CCN2CCN(CC(=O)O)CC2)CCN(CC(=O)O)CC1</smiles>

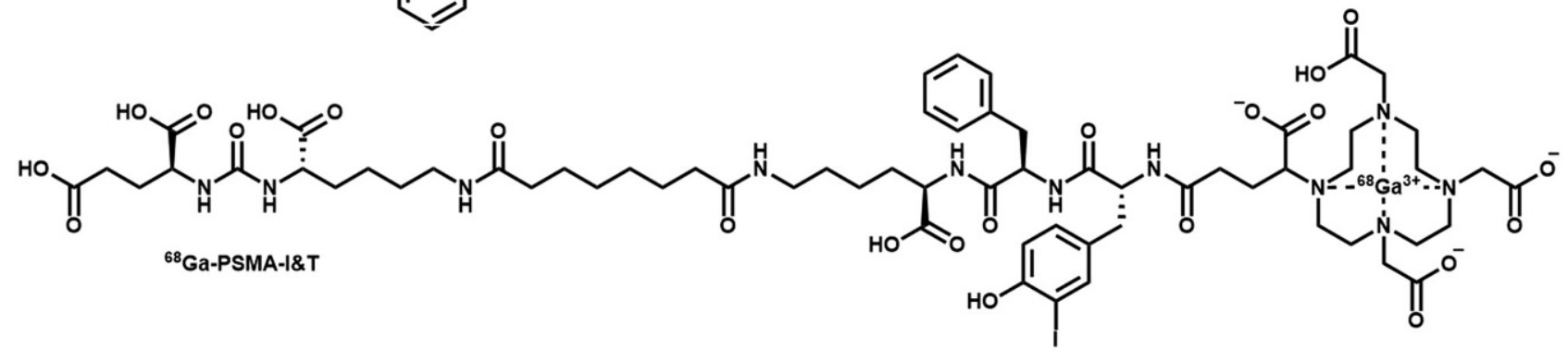

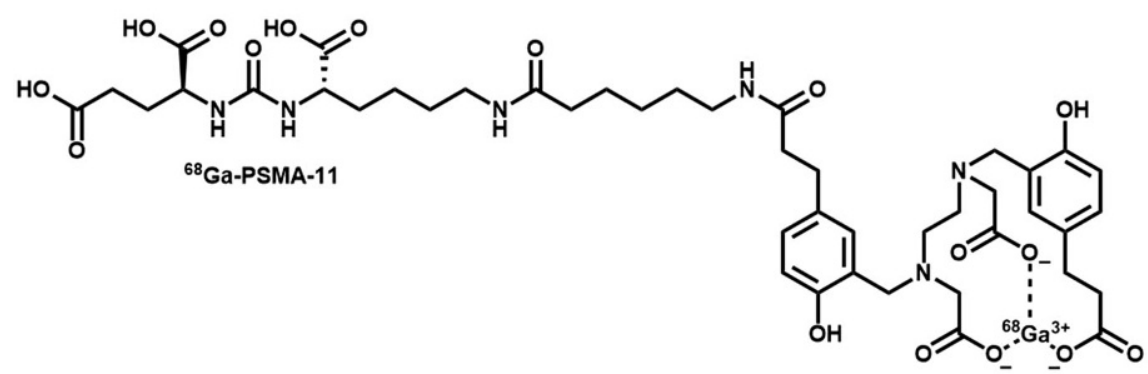

Fig. 2 Different Gallium-68 ( $\left.{ }^{68} \mathrm{Ga}\right)$-labelled PSMA tracer structures

\section{PSMA PET/CT acquisition}

Internationally, Gallium-68 $\left({ }^{68} \mathrm{Ga}\right)$-labelled PSMA tracers are most commonly used. The PSMA-PET/CT is usually performed with low-dose CT from head to upper thigh. Image acquisition starts 50-60 minutes after injection of $1.8-2.2 \mathrm{MBq} / \mathrm{kg}{ }^{68} \mathrm{Ga}-\mathrm{PSMA}$ in accordance with the European Nuclear Medicine guidelines [17]. Radiation dose is approximately $2-4 \mathrm{mSv}$. Patients do not need to fast or temporarily stop intake of their medication, however, they need to be well hydrated (e.g. oral intake of $500 \mathrm{ml}$ of water during a 2 hour period prior to acquisition). Furosemide administration (20 mg i.v. shortly before or after i.v. administration of the radiopharmaceutical) may be used to reduce the high residual activity in the urinary system, which may lead to artefacts or even false positive findings.

\section{PSMA/PET in primary staging prostate cancer}

\section{Gallium-68-labelled PSMA tracers}

In 2011, Afshar-Oromieh et al. reported on PET/CT images obtained with ${ }^{68}$ Ga-PSMA-HBED-CC in a 67 - year-old PCa patient with an increased PSA level and a history of radiotherapy to prostate and hormone therapy. Whereas the performed ${ }^{18} \mathrm{~F}-\mathrm{FECH}$ PET/CT did not detect any lesions, ${ }^{68} \mathrm{Ga}-\mathrm{PSMA}-\mathrm{HBED}-\mathrm{CC}$ showed a lesion adjacent to the urinary bladder [18]. This publication marked the start of the ${ }^{68} \mathrm{Ga}$-labelled PSMA PET/CT usage for PCa diagnostics. Subsequently, studies focusing on the setting of biochemical recurrence, showed high diagnostic value of ${ }^{68} \mathrm{Ga}-$ PSMA PET/CT for Pca [19, 20]. Additionally, a vast number of initial studies demonstrated promising results of ${ }^{68} \mathrm{Ga}$-PSMA PET/CT in primary PCa detection (Tab. 1 and 2; [21-24]).

Hope et al. performed a meta-analysis to clarify detection rate of ${ }^{68} \mathrm{Ga}$-PSMA PET/CT for lymph node detection in the setting of primary staging of PCa [20]. The study comprised five studies, including one prospective study [24], involving 266 patients mostly classified as having intermediate to high risk PCa. In all studies, PET results were compared to histopathology as a reference. A lesion-based sensitivity, specificity, positive predictive value (PPV), negative predictive value (NPV) and an accuracy of respectively; $74 \%$ (95\% CI 51-89), 96\% (95\% CI 
Fig. 3 Different ${ }^{18}$ Flourine $\left({ }^{18} \mathrm{~F}\right)$-labelled PSMA tracer structures<smiles>O=C(O)CCC(NC(=O)N[C@@H](CCCCNC(=O)c1ccc(F)nc1)C(=O)O)C(=O)O</smiles><smiles>O=C(O)CCC(NC(=O)N[C@@H](CSCc1ccc(F)cc1)C(=O)O)C(=O)O</smiles>

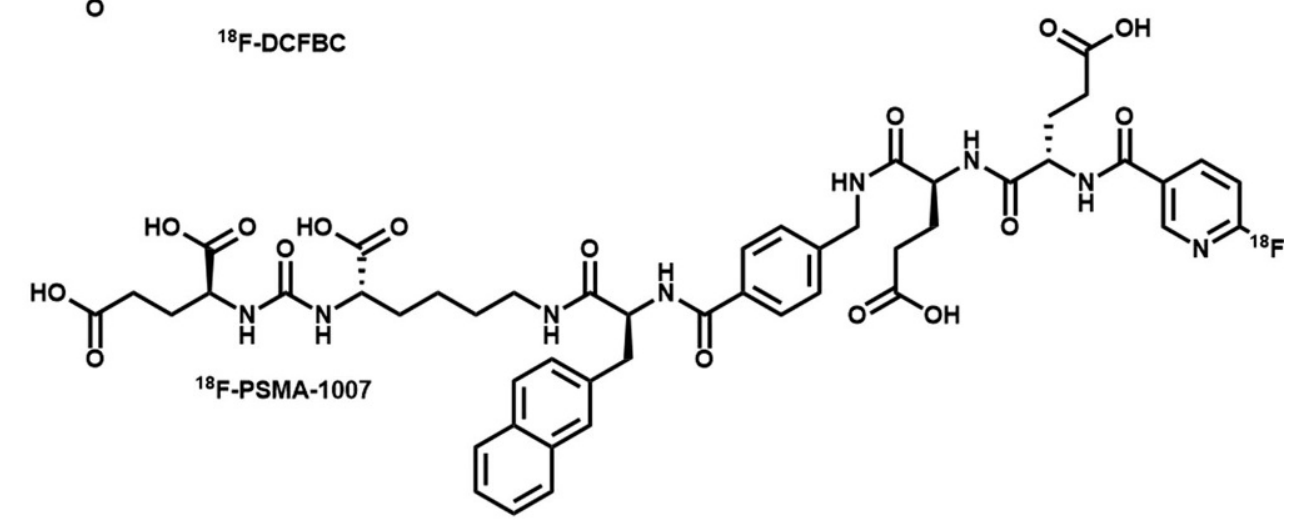

85-99), 93\% (95\% CI 86-99), 85\% (95\% CI 75-93) and $86 \%$ (95\% CI 72-92) was observed.

After the publication of this meta-analysis, Luiting et al. recently also reviewed diagnostic performance of ${ }^{68} \mathrm{Ga}$-PSMA PET/CT for lymph node detection in primary staging in men with PCa [25]. In this review, 11 studies were included: two prospective studies $[24,25]$ ( $n=63$ patients) with one using ${ }^{68} \mathrm{Ga}-$ PSMA PET/MRI as diagnostic scan $(n=33)$ and nine retrospective studies ( $n=696$ patients). In all studies, histopathology was referred to as the gold standard. Patient-based sensitivity and specificity ranges of respectively $64-100 \%$ and $90-95 \%$ were found in the prospective studies. Lesion-based sensitivity and specificity ranges were $50-58 \%$ and $96-100 \%$, respectively. In the retrospective studies, the sensitivity and specificity range was $33.3-100 \%$ and $80-100 \%$, respectively. With regard to the lesion-based analysis, they found a sensitivity and specificity range of 24.4-96.1\% and $98.6-100 \%$, respectively [26]. Especially sensitivity was lower in comparison with the previously discussed meta-analysis by Hope et al. [20] who included significantly less studies.

The PEPPER-study initiated by the University Medical Center Utrecht in the Netherlands was neither included in the review of Luiting et al. [26], nor in the systematic review of Hope et al. [20]. This was a prospective study evaluating the diagnostic accuracy of ${ }^{68} \mathrm{Ga}$-PSMA PET/CT for lymph node detection in primary staging in men with PCa with histopathology as a reference. Patients where included if they had newly diagnosed prostate cancer, negative skeletal scintigraphy, $>10 \%$ risk for lymph node metastasis fol- lowing (MSKCC)-nomogram and were eligible for an ePLND. A total of 103 patients where included. In six patients ePLND was canceled, because of ${ }^{68} \mathrm{Ga}-\mathrm{PSMA}$ PET/CT findings (i.e. PET positive distant lesions) illustrated in Fig. 4. A patient-based sensitivity and specificity of respectively $41.5 \%$ (95\% CI 26.7-57.8) and $90.9 \%$ (95\% CI 79.3-96.6) was found for detecting lymph node metastasis, and positive and negative predictive values of $77.3 \%$ (95\% CI 54.2-91.3) and 67.6\% (95\% CI 55.6-77.7), respectively. Furthermore, a template-based (i.e. left/right and lateral/medial of the external iliac artery) sensitivity, specificity, PPV and NPV of $35.1 \%$ (59\% CI 23.2-48.9), 96.4\% (95\% CI 93.5-98.1), 64.5\% (95\% CI 45.4-80.2) and 89.0\% (95\% CI 85.0-92.0), respectively, was observed [27].

Hofman et al. recently published the first prospective, randomized, multi-center phase 3 study, evaluating accuracy for metastases detection with PSMA PET/CT compared with conventional imaging (CT and skeletal scintigraphy) [28]. A total of 302 patients with high risk features, being considered for radical prostatectomy or radiotherapy with curative intent, were included. The patients were randomly assigned for staging with either conventional imaging $(n=152)$ or ${ }^{68} \mathrm{Ga}-\mathrm{PSMA} \mathrm{PET} / \mathrm{CT}(n=150)$. The cases where considered positive if they met one hard criterion (histopathology showing $\mathrm{PCa}$, or change of a bone lesion to a sclerotic or blastic state on followup imaging) or three from the soft criteria as not all the patients underwent prostatectomy $(n=126)$ and/or ePLND $(n=83)$. These soft criteria included: (1) typical appearance of multi-focal metastatic disease; (2) a metastatic lesion on an imaging modality 
Table $1 \quad$ Lesion-based sensitivity, specificity, positive predictive value (PPV), negative predictive value (NPV)

Table 2 Patient-based sensitivity, specificity, positive predictive value (PPV), negative predictive value (NPV)

\begin{tabular}{|c|c|c|c|c|}
\hline Author & Sensitivity & Specificity & PPV & NPV \\
\hline Hope et al. [20] & $74 \%(95 \% \mathrm{Cl} 51-89)$ & $96 \%(95 \% \mathrm{Cl} 85-99)$ & $93 \%(95 \% \mathrm{Cl} 86-99)$ & $85 \%(95 \%$ Cl 75-93) \\
\hline Luiting et al. pros. [25] & $50-58 \%$ & $96-100 \%$ & - & - \\
\hline Luiting et al. retr. [25] & $24.4-96.1 \%$ & $98.6-100 \%$ & - & - \\
\hline $\begin{array}{l}\text { Van Kalmthout et al. } \\
{[26]^{\mathrm{a}}}\end{array}$ & $\begin{array}{l}35.1 \%(59 \% \mathrm{Cl} \\
23.2-48.9)\end{array}$ & $\begin{array}{l}96.4 \%(95 \% \mathrm{Cl} \\
93.5-98.1)\end{array}$ & $\begin{array}{l}64.5 \%(95 \% \mathrm{Cl} \\
45.4-80.2)\end{array}$ & $\begin{array}{l}89.0 \%(95 \% \mathrm{Cl} \\
85.0-92.0)\end{array}$ \\
\hline
\end{tabular}

\begin{tabular}{llllll}
\hline $\begin{array}{l}\text { Author } \\
\text { Luiting et al. pros. }\end{array}$ & Sensitivity & Specificity & PPV & NPV \\
[25] & & $90-95 \%$ & - & - \\
\hline $\begin{array}{l}\text { Luiting et al. retr. [25] } \\
\text { Van Kalmthout et al. }\end{array}$ & $\begin{array}{l}41.3-100 \% \\
\text { [26] }\end{array}$ & $80-100 \%$ & - & - \\
\hline Hofman et al. [27] & $26.7-57.8)$ & $90.9 \%(95 \% \mathrm{Cl}$ & $77.3 \%(95 \% \mathrm{Cl}$ & $67.6 \%(95 \% \mathrm{Cl}$ \\
& & $79.3-96.6)$ & $54.2-91.3)$ & $55.6-77.7)$ \\
\hline
\end{tabular}

other than the one done as the index scan; (3) increase in size or number of lesions from one imaging exam to the next; (4) decrease in size or number of lesions from one imaging exam to the next, following appropriate treatment; (5) lesion associated with clinical symptoms suggesting malignancy; (6) patient received localized treatment for imaging finding; (7) increase in PSA in keeping with clinical scenario of progression, or decrease in response to treatment; and (8) unequivocal persistence of positive finding on repeated imaging at 6 months in patients with a PSA concentration of $>0.2 \mathrm{ng} / \mathrm{mL}$ at least three weeks following prostatectomy. It was found that PSMA PET/CT had a significant $(p<0.0001)$ greater accuracy than conventional imaging; $92 \%$ (95\% CI 88-95) versus 65\% (95\% CI 60-69). They also found a lower patient-based sensitivity of $38 \%$ (95\% CI 24-52) versus $85 \%$ (95\% CI 74-96) and specificity of 91\% (95\% CI 85-97) versus 98\% (95\% CI 95-100) for conventional imaging compared to PSMA PET/CT. Compared to the PEPPER-study, Hofman et al. (2020) found a much higher patient-based sensitivity: $41.5 \%$ (95\% CI 26.7-57.8) versus 85\% (95\% CI 74-96). An explanation for this is that Hofman et al. [27] did not only use histopathology as reference and therefore may have overestimated true positive lesions.

\section{${ }^{18}$ Flourine-labelled PSMA tracers}

As an alternative for ${ }^{68} \mathrm{Ga}-\mathrm{PSMA},{ }^{18}$ Flourine-labelled PSMA tracers were developed, most notably ${ }^{18} \mathrm{~F}$-DCFPyL and ${ }^{18}$ F-PSMA-1007 [29]. The radiotracer ${ }^{18} \mathrm{~F}$-DCFPyL was first described in literature by Chen et al. in 2011 [30]. The first clinical experience in humans was obtained four years later, consisting of nine hormonenaïve and castration-resistant patients. As no severe adverse events occurred in these nine men, this study not only demonstrated the tumor uptake of ${ }^{18} \mathrm{~F}-\mathrm{DCF}-$ PyL, but also its safety [31]. Studies evaluating diagnostic performance of ${ }^{18} \mathrm{~F}$-DCFPyL PET/CT in recur- rent PCa showed promising results [32]. With regard to diagnostic performance of ${ }^{18} \mathrm{~F}$-labelled PSMA tracers in primary PCa however, only a small number of studies was published and initial results of prospective studies are awaited.

In 2018, Gorin et al. prospectively evaluated diagnostic performance of preoperative ${ }^{18} \mathrm{~F}$-DCFPyL $\mathrm{PET} / \mathrm{CT}$ in 25 men with high risk PCa being eligible for prostatectomy and ePLND. When compared to histopathology findings patient-based sensitivity and specificity was respectively $71.4 \%$ (95\% CI 29.0-96.3) and $88.9 \%$ (95\% CI 65.3-98.6). Lesion-based sensitivity and specificity was $66.7 \%$ (95\% CI 29.9-92.5) and 97.7\% (95\% CI 80.1-98.5), respectively [33].

At present, the diagnostic performance of ${ }^{18} \mathrm{~F}-\mathrm{DCF}$ PyL and ${ }^{18}$ F-PSMA-1007 in the setting of initial staging of PCa with histopathology reference are currently under investigation in prospective trials conducted at the Amsterdam UMC, location VUmc (the SALT-study; NL6754), and the Canisius Wilhelmina Ziekenhuis in Nijmegen (the MINT-study; NL7428). The results of these studies are expected soon.

\section{Discussion}

In this paper, we aimed to summarize the current knowledge derived from the literature as well as the authors' experiences on PSMA PET/CT in initial staging of PCa. Overall, the diagnostic accuracy of PSMA PET/CT for lymph node detection in primary staging in men with PCa appears to be very promising with a high lesion- and patient-based specificity [19, 20, 26, 28, 33]. The superiority of PSMA PET/CT for the detection of PCa metastases in primary setting compared to conventional imaging (CT and skeletal scintigraphy) has been shown by the recent randomized-controlled trial by Hofman et al. [28]. These results support the (inter)national implementation of PSMA PET/CT as a first-line diagnostic modality for primary PCa stag- 
Fig. 4 Case description. Transversal (a) and frontal (c) fused ${ }^{68} \mathrm{Ga}-$ PSMA-PET/CT and transversal (b) and frontal (d) PET images of a 80-years old man with $\mathrm{CT} 3 \mathrm{a}$, Gleason $4+4=8 \mathrm{PCa}$ (initial PSAlevel of $33 \mathrm{ng} / \mathrm{ml}$ ) and considered candidate for ePLND (MSKCC-nomogram: 77\% risk of lymph node involvement). ${ }^{68} \mathrm{Ga}-\mathrm{PSMA}-\mathrm{PET} / \mathrm{CT}$ showed PSMA avid disease in the prostate region $(\mathbf{a}, \mathbf{b})$, as well as extensive bilateral (extra-) pelvic lymph node involvement $(\mathbf{c}, \mathbf{d})$. During the post-PET tumor board meeting, it was decided to cancel ePLND and start androgen deprivation therapy, followed by a PSA-decline to $0.24 \mathrm{ng} / \mathrm{ml}$
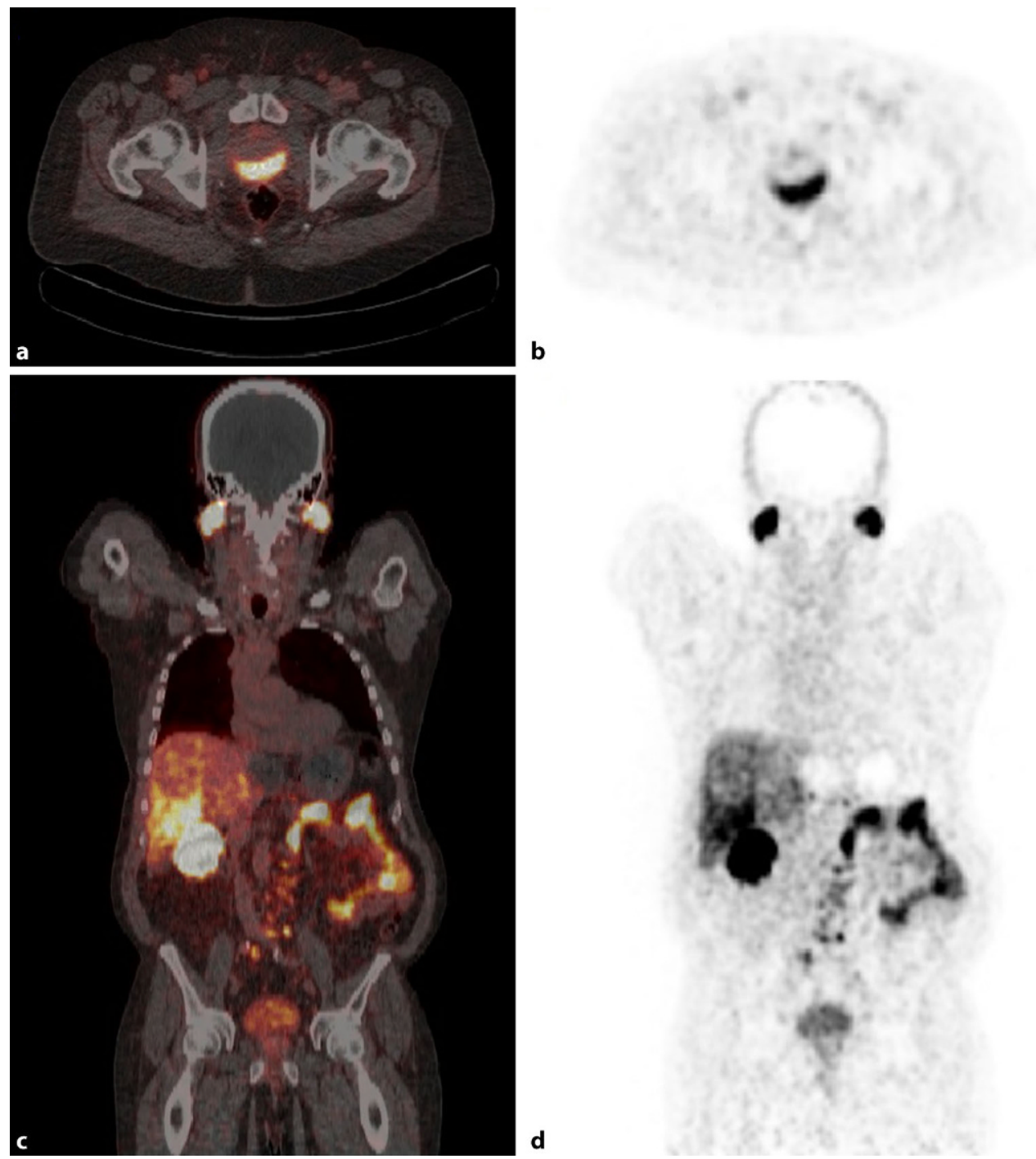

ing instead of conventional imaging (CT and skeletal scintigraphy).

However, despite its high specificity, PSMA PET/CT had a moderate to low patient-, and lesion-based sensitivity $[19,20,26,28,33]$ indicating that a negative PSMA PET/CT cannot rule out lymph node metastasis and therefore is not able to replace ePLND for lymph node detection. Nevertheless, because of the high specificity, a positive PSMA PET/CT can change treatment management. In the PEPPER-study, an ePLND was avoided in $5.8 \%$ of the patients because of distant metastases on PSMA PET/CT [27]. Therefore, an invasive and expensive intervention could be prevented.

This implies that the implementation of PSMA PET/CT could be cost-effective. A recent study from the Netherlands evaluated the cost-effectiveness of PSMA PET/CT in primary staging of Pca- versus ePLND-based staging on an interactive model [34]. Effectiveness (Quality Adjusted Life Year's (QALYs) combining utility score and survival) and the cost analysis (from a healthcare perspective) were mod- elled over lifetime. Healthcare states were either: no evidence of disease, biochemical recurrence, salvage treatment, palliative care or death. They found a cost saving with PSMA PET/CT of $€ 3074$ (95\% CI -3515-2330), but at the possible expense of a small QALY loss of 0.07 (95\% CI -0.13-0.02) when ePLND was considered the gold standard with a sensitivity and specificity of $100 \%$. However, this study evaluated the total replacement of ePLND with PSMA PET/CT and did not include the ability of PSMA PET/CT to detect distant metastases. If accounted for the detection of distant metastases, more cost-savings and better effectiveness can be expected due to earlier treatment of distant metastases detected by PSMA PET/CT. As mentioned before, due to low sensitivity an ePLND is still required in patients with negative PSMA PET/CT, but ePLND may possibly be omitted in patients with positive PSMA PET/CT findings. Therefore prospective cost-effectiveness studies are needed. 
In this paper, we focused on the radiotracers that are commonly used in the Netherlands. There is no study that compared diagnostic accuracy of ${ }^{68} \mathrm{Ga}$ labelled PSMA to ${ }^{18} \mathrm{~F}$-labelled PSMA radiotracers in patients with newly diagnosed PCa. However, there are some studies that compared the diagnostic accuracy in relapse PCa. Dietlein et al. compared the clinical use of ${ }^{68} \mathrm{Ga}$-PSMA-HBED-CC tracer and ${ }^{18} \mathrm{~F}$-DCFPyL tracer for PSMA PET imaging in 14 patients with relapse PCa [15]. All the suspicious lesions identified by the ${ }^{68} \mathrm{Ga}$-PSMA-HBED-CC tracer where also identified by the ${ }^{18} \mathrm{~F}-\mathrm{DCFPyL}$ tracer. However, the ${ }^{18} \mathrm{~F}$-DCFPyL tracer identified additional lesions in three patients. Also a higher maximal Standardized Uptake Value $\left(S V_{\max }\right)$ in PSMA positive lesions and higher mean tumor to background ratios (when using kidney, spleen or parotid as reference organ) were found in ${ }^{18} \mathrm{~F}$-DCFPyL PET/CT compared to ${ }^{68} \mathrm{Ga}$ PSMA-HBED-CC PET/CT. The higher detection rate of the ${ }^{18} \mathrm{~F}$-DCFPyL tracer in this study can be explained by the higher injected dose (mean dose of $318.4 \mathrm{Mbq} \pm 59.0 \mathrm{MBq}$ versus $128.3 \mathrm{MBq} \pm 35.9 \mathrm{MBq}$ ) of ${ }^{18} \mathrm{~F}$-DCFPyL. A consecutive study from Dietlein et al. confirmed the non-inferiority of the ${ }^{18} \mathrm{~F}$-DCFPyL tracer compared to the ${ }^{68} \mathrm{Ga}$-PSMA-HBED-CC tracer in the diagnostic performances of relapse PCa [14]. They retrospectively included 62 patients who underwent ${ }^{18} \mathrm{~F}$-DCFPyL- and 129 patients who underwent ${ }^{68} \mathrm{Ga}$-PSMA-HBED-CC PET/CT, subdivided by previous therapy (i.e. prostatectomy or radiotherapy). They found a higher detection rate in ${ }^{18} \mathrm{~F}$-DCFPyL imaging with PSA levels between $0.5-3.5 \mu \mathrm{g} / \mathrm{L}$ in prostatectomy patients.

Based on these studies and due to the logistic features of ${ }^{18} \mathrm{~F}$-labelled PSMA tracers, we expect that these tracers will ultimately be preferred over ${ }^{68} \mathrm{Ga}$ PSMA. A prospective comparison in newly diagnosed PCa with histopathologic reference is needed.

\section{Conclusion}

Overall, we can conclude that regarding primary PCa, the accuracy of PSMA PET/CT is superior to that of conventional imaging (CT and skeletal scintigraphy). PSMA PET/CT has a high specificity but a moderate sensitivity for lymph node detection in primary PCa. Therefore, an ePLND is still required for initial PCa staging in PSMA PET/CT negative patients. However, a positive PSMA PET/CT may induce management changes.

In the current Dutch oncology guidelines, PSMA PET/CT is recommended for two indications: (1) metastasis detection in primary $\mathrm{PCa}$ when indicated (i.e. PSA $\geq 20 \mathrm{ng} / \mathrm{mL}$, cT3 PCa, Gleason score $\geq 8$, or bone pain) and (2) for the detection of biochemical recurrent PCa in patients with a history of prostatectomy or radiotherapy with a PSA value of $>0.2 \mathrm{ng} / \mathrm{mL}$. For adequate local staging, MRI is still recommended.
Open Access This article is distributed under the terms of the Creative Commons Attribution 4.0 International License (http://creativecommons.org/licenses/by/4.0/), which permits unrestricted use, distribution, and reproduction in any medium, provided you give appropriate credit to the original author(s) and the source, provide a link to the Creative Commons license, and indicate if changes were made.

\section{References}

1. Siegel RL, Miller KD, Jemal A. Cancer statistics, 2019. CA Cancer JClin. 2019;69(1):7-34.

2. Integraal Kankercentrum Nederland. Incidentie, prostaatkanker, aantal. 2020. Available from https://www.iknl.nl/ nkr-cijfers. Accessed 30 Apr 2020.

3. Gakis G, Boorjian SA, Briganti A, et al. The role of radical prostatectomy and lymph node dissection in lymph node-positive prostate cancer: a systematic review of the literature. Eur Urol. 2014;66(2):191-9.

4. European Association of Urology. EAU-EANM-ESTROESUR-SIOG Guidelines on Prostate Cancer 2020. Available from https://uroweb.org/guideline/prostate-cancer/. Accessed 30 Apr 2020.

5. Heesakkers RA, Hövels AM, Jager GJ, et al. MRI with a lymph-node-specific contrast agent as an alternative to CT scan and lymph-node dissection in patients with prostate cancer: a prospective multicohort study. Lancet Oncol. 2008;9(9):850-6.

6. Briganti A, Chun FK, Salonia A, et al. Complications and other surgical outcomes associated with extended pelvic lymphadenectomy in men with localized prostate cancer. Eur Urol. 2006;50(5):1006-13.

7. Lavalaye J, Kaldeway P, van Melick HH. Diffuse bone metastases on (68)Ga-PSMA PET-CT in a patient with prostate cancer and normal bone scan. Eur J Nucl Med Mol Imaging. 2016;43(8):1563-4.

8. Evangelista L, Briganti A, Fanti S, et al. New clinical indications for (18)F/ (11)C-choline, new tracers for positron emission tomography and a promising hybrid device for prostate cancer staging: a systematic review of the literature. Eur Urol. 2016;70(1):161-75.

9. Afshar-Oromieh A, Avtzi E, Giesel FL, et al. The diagnostic value of PET/CT imaging with the (68)Ga-labelled PSMA ligand HBED-CC in the diagnosis of recurrent prostate cancer. Eur J Nucl Med Mol Imaging. 2015;42(2):197-209.

10. Nederlandse Vereniging voor Urologie. Evidence based richtlijn voor de diagnostiek en behandeling van prostaatcarcinoom. Available from https://www.oncoline.nl/ richtlijn. Accessed 30 Apr 2020.

11. Silver DA, Pellicer I, Fair WR, Heston WD, Cordon-Cardo C. Prostate-specific membrane antigen expression in normal and malignant human tissues. Clin Cancer Res. 1997;3(1):81-5.

12. Leung K. Quenched indocyanine green-anti-prostate-specific membrane antigen antibody J591. Molecular Imaging and Contrast Agent Database (MICAD). Bethesda: National Center for Biotechnology Information; 2013. Dec 8 [updated 2012 Mar 1].

13. Afshar-Oromieh A, Malcher A, Eder M, et al. PET imaging with a [68Ga]gallium-labelledPSMAligandfor the diagnosis of prostate cancer: biodistribution in humans and first evaluation of tumour lesions. Eur J Nucl Med Mol Imaging. 2013;40(4):486-95.

14. Dietlein F, Kobe C, Neubauer S, et al. PSA-stratified performance of (18)F- and (68)ga-PSMA PET in patients with biochemical recurrence of prostate cancer. J Nucl Med. 2017;58(6):947-52. 
15. Dietlein M, Kobe C, Kuhnert G, et al. Comparison of [(18)F]DCFPyL and [(68)Ga]Ga-PSMA-HBED-CC for PSMA-PET imaging in patients with relapsed prostate cancer. Mol Imaging Biol. 2015;17(4):575-84.

16. Kesch C, Kratochwil C, Mier W, Kopka K, Giesel FL. (68)ga or (18)F for prostate cancer imaging? J Nucl Med. 2017;58(5):687-8.

17. Fendler WP, Eiber M, Beheshti M, et al. (68)Ga-PSMA PET/CT: Joint EANM and SNMMI procedure guideline for prostate cancer imaging: version 1.0. Eur J Nucl Med Mol Imaging. 2017;44(6):1014-24.

18. Afshar-Oromieh A, Haberkorn U, Eder M, Eisenhut M, Zechmann CM. 68Ga]Gallium-labelled PSMA ligand as superior PET tracer for the diagnosis of prostate cancer: comparison with 18F-FECH. Eur J Nucl Med Mol Imaging. 2012;39(6):1085-6.

19. Perera M, Papa N, Roberts M, et al. Gallium-68 prostatespecific membrane antigen positron emission tomography in advanced prostate cancer-updated diagnostic utility, sensitivity, specificity, and distribution of prostate-specific membrane antigen-avid lesions: a systematic review and meta-analysis. Eur Urol. 2020;77(4):403-17.

20. Hope TA, Goodman JZ, Allen IE, Calais J, Fendler WP, Carroll PR. Metaanalysis of (68)Ga-PSMA-11 PET accuracy for the detection of prostate cancer validated by histopathology. J Nucl Med. 2019;60(6):786-93.

21. Budaus L, Leyh-Bannurah SR, Salomon G, et al. Initial experience of (68)Ga-PSMA PET/CT imaging in high-risk prostate cancer patients prior to radical prostatectomy. Eur Urol. 2016;69(3):393-6.

22. Herlemann A, Wenter V, Kretschmer A, et al. (68)GaPSMA positron emission tomography/computed tomography provides accurate staging of lymph node regions prior to lymph node dissection in patients with prostate cancer. Eur Urol. 2016;70(4):553-7.

23. Maurer T, Gschwend JE, Rauscher I, et al. Diagnostic efficacy of (68)Gallium-PSMA positron emission tomography compared to conventional imaging for lymph node staging of 130 consecutive patients with intermediate to high risk prostate cancer. J Urol. 2016;195(5):1436-43.

24. van Leeuwen PJ, Emmett L, Ho B, et al. Prospective evaluation of $68 \mathrm{Gallium}$-prostate-specific membrane antigen positron emission tomography/computed tomography for preoperative lymph node staging in prostate cancer. BJU Int. 2017;119(2):209-15.

25. Park SY, Zacharias C, Harrison C, et al. Gallium 68 PSMA$11 \mathrm{PET} / \mathrm{MR}$ imaging in patients with intermediate- or highrisk prostate cancer. Radiology. 2018;288(2):495-505.

26. Luiting $\mathrm{HB}$, van Leeuwen PJ, Busstra MB, et al. Use of gallium-68 prostate-specific membrane antigen positronemission tomography for detectinglymph nodemetastases in primary and recurrent prostate cancer and location of recurrence after radical prostatectomy: an overview of the currentliterature. BJU Int. 2020;125(2):206-14.

27. van Kalmthout LWM, van Melick HE, Lavalaye J, et al. Prospective validation of Gallium-68 prostate specific membrane antigen-positron emission tomography/ computerized tomography in primary staging of patients with prostate cancer. J Urol. 2019; https://doi.org/10.1097/ JU.0000000000000531.

28. Hofman MS, Lawrentschuk N, Francis RJ, et al. Prostatespecific membrane antigen PET-CT in patients with highrisk prostate cancer before curative-intent surgery or radiotherapy (proPSMA): a prospective, randomised, multicentre study. Lancet. 2020;395(10231):1208-16.

29. Giesel FL, Hadaschik B, Cardinale J, et al. F-18 labelled PSMA-1007: biodistribution, radiation dosimetry and histopathological validation of tumor lesions in prostate cancer patients. Eur J Nucl Med Mol Imaging. 2017;44(4):678-88.

30. Chen Y, Pullambhatla M, Foss CA, et al. 2-(3-\{1-Carboxy5-[(6-[18F]fluoro-pyridine-3-carbonyl)-amino]-pentyl $\}$ ureido)-pen tanedioic acid, [18F]DCFPyL, a PSMA-based PET imaging agent for prostate cancer. Clin Cancer Res. 2011;17(24):7645-53.

31. Szabo Z, Mena E, Rowe SP, et al. Initial evaluation of [(18)F]DCFPyL for prostate-specific membrane antigen (PSMA)-targeted PET imaging of prostate cancer. Mol Imaging Biol. 2015;17(4):565-74.

32. Treglia G, Annunziata S, Pizzuto DA, Giovanella L, Prior JO, Ceriani L. Detection rate of (18)F-labeled PSMA PET/CT in biochemical recurrent prostate cancer: a systematic review and a meta-analysis. Cancers. 2019;11(5):710.

33. Gorin MA, Rowe SP, Patel HD, et al. Prostate specific membrane antigen targeted (18)F-DCFPyL positron emission tomography/computerized tomography for the preoperative staging of high risk prostate cancer: results of a prospective, phase II, single center study. J Urol. 2018;199(1):126-32.

34. Scholte M, Barentsz JO, Sedelaar JPM, Gotthardt M, Grutters JPC, Rovers MM. Modelling Study with an interactive model assessing the cost-effectiveness of (68)Ga prostatespecific membrane antigen positron emission tomography/computed tomography and nano magnetic resonance imaging for the detection of pelvic lymph node metastases in patients with primary prostate cancer. Eur Urol Focus. 2020Sep 15;6(5):967-74.

Esmée C.A. van der Sar MD, medical researcher nuclear medicine

Ludwike M. van Kalmthout MD, PhD student, Resident Radiation Oncology

M.G.E.H. Lam PhD, nuclear medicine physician 